\title{
Estimating the economic benefits of high-speed rail in China: A new perspective from the connectivity improvement
}

\author{
Zhaohui Chong \\ Shantou University \\ zhchong@stu.edu.cn \\ Zhenhua Chen \\ The Ohio State University \\ chen.7172@osu.edu
}

\author{
Chenglin Qin (corresponding author) \\ Jinan University \\ qinchlin@jnu.edu.cn
}

\begin{abstract}
This paper evaluates the economic benefits of high-speed rail (HSR) in China, with a focus on the connectivity change resulting from HSR development. The effect of HSR, measured in degree centrality, is assessed using a spatial econometric modeling technique based on a panel dataset that covers 268 Chinese cities from 2008-2015. To provide a robust assessment, statistical issues including heterogeneous effects, endogeneity, and spatial dependence are addressed simultaneously in the spatial panel modeling process. Our empirical results confirm that connectivity improvement brought by HSR plays a vital role in facilitating economic growth. Specifically, the contribution of HSR to urban economic growth is found to be 0.11 , most of which comes from a local effect rather than a spillover effect. Overall, the research findings suggest that urban economic growth can benefit from the development of HSR.
\end{abstract}

Keywords: Urban economic growth, connectivity improvement, HSR network, spillover effect

\section{Introduction}

Despite plethora of studies has examined the benefits of transportation infrastructure using various methods, such as cost-benefit analysis (Elhorst \& Oosterhaven, 2008; Ansar, Flyvbjerg, Budzier, \& Lunn, 2016) and econometric analysis (Chen \& Haynes, 2015; Qin, 2017; Lin, 2017), the research findings are inconsistent. For instance, some studies indicate that transportation infrastructure plays significant roles, such as changing travel behaviors and facilitating interregional trade flows (Handy, Cao, \& Mokhtarian, 2005; Zhang, Hong, Nasri, \& Shen, 2012; Chatman, 2014), whereas other studies suggest that the economic benefit of transportation infrastructure may not always be significant (Baum-Snow, 2013).

Some studies, such as Morten and Oliveira (2016), indicate that the upgrade of transportation infrastructure may not only eliminate obstacles to migration, but may also improve intercity connectivity, thus facilitating knowledge spillovers through an improved passenger mobility. To measure the benefit of transportation system expansion or infrastructure improvement to local economic growth,

Copyright 2019 Zhaohui Chong, Chenglin Qin, \& Zhenhua Chen

http://dx.doi.org/10.5198/jtlu.2019.1264

ISSN: 1938-7849 | Licensed under the Creative Commons Attribution - Noncommercial License 4.0

The Journal of Transport and Land Use is the official journal of the World Society for Transport and Land Use (WSTLUR) and is published and sponsored by the University of Minnesota Center for Transportation Studies. 
connectivity is often considered an important indicator (Alstadt, Weisbrod, \& Cutler, 2012). Although the economic benefits of transportation infrastructure have been justified by the new economic geography theory, the empirical assessment of the effects is still challenging due to the endogeneity issue and spillover effect that is potentially involved (Graham \& Dender, 2011). This paper fills this gap by providing new evidence to help to answer the following three questions: How significant is the benefit of HSR on urban economic growth in China? Does the heterogenous influence exist for cities with different economic conditions? And to what extent does the magnitude of impact vary between direct and indirect (spillover) effects?

The HSR network has experienced unprecedented development over the past decade in China, which provides a good case for studying its impact on urban economic activities. As shown in Figure 1, the so-called "Four Vertical and Four Horizontal" HSR network, which consists of four north-south bound and four east-west bound HSR trunk lines of over $23,000 \mathrm{~km}$, had almost been completed by the end of 2017. To date, the interconnected HSR network serves most major Chinese cities and the intercity travel time has been substantially reduced. Although the total track length of HSR only accounts for one fifth of the total rail networks in China, more than $60 \%$ of the rail passenger demand is transported by HSR. In addition, China's HSR network is still under expansion. According to the 13th Five-Year Plan (2016-2020), the total track length of HSR is expected to reach 30,000 km by 2020 , with an objective to serve more than $80 \%$ of the cities in China.

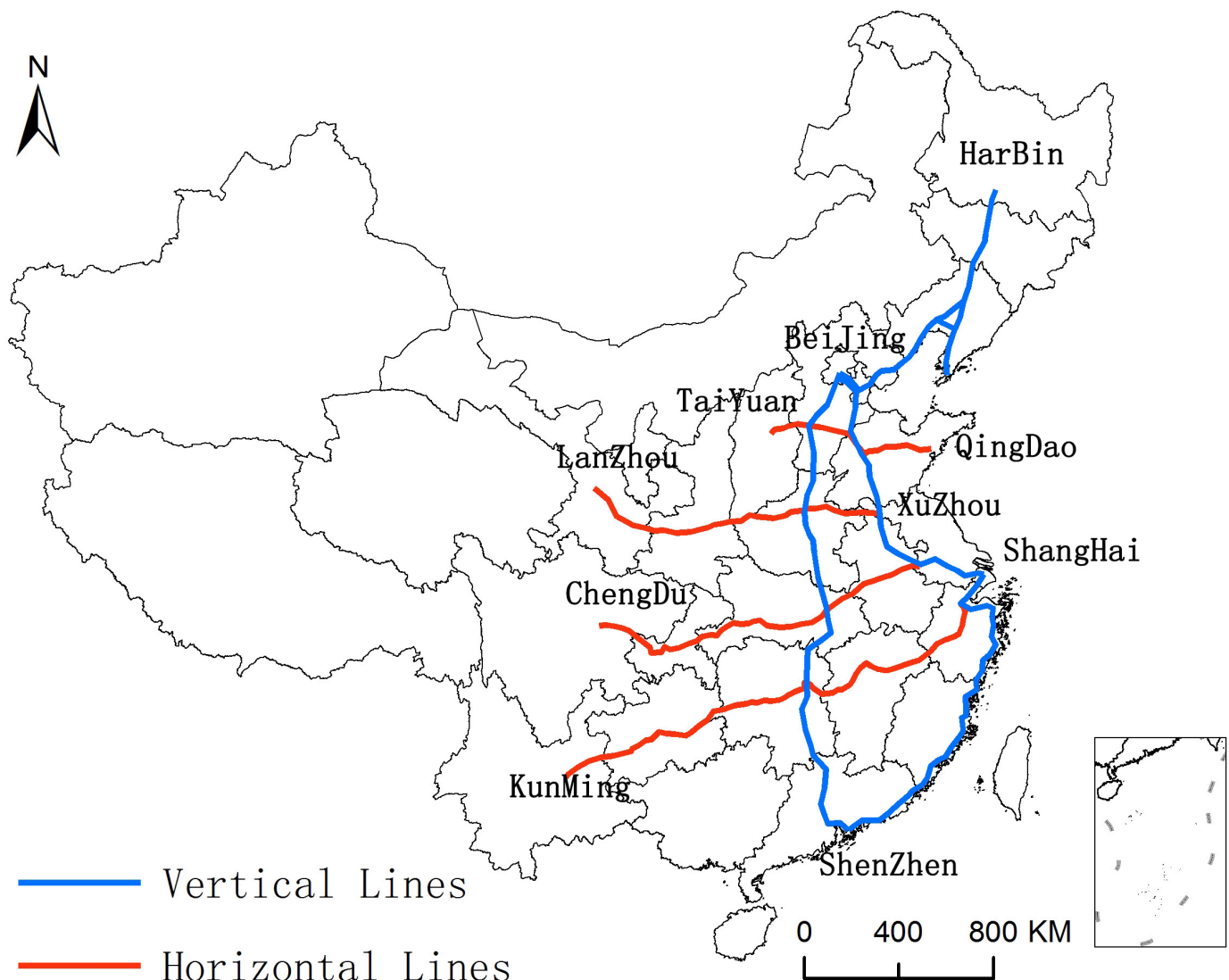

Figure 1. China's "four vertical and four horizontal" HSR networks Source: the authors. 
This paper has the following research highlights compared with previous studies. First, we focus on evaluating the economic benefits of the HSR network from the perspective of connectivity improvement. The connectivity indicator captures the temporal and spatial evolution of China's HSR network expansions. Second, the heterogenous effects of cities with different economic conditions are measured using interaction item model and spillover effects, which are controlled in a spatial panel modeling procedure. Hence, the assessment is able to provide a comprehensive examination of heterogenous and spatial effects of the HSR network on regional economic performance. Lastly, the endogeneity issue is also examined using the dynamic panel (IV-GMM) regression method. Such a modeling procedure is important as it improves the robustness of the results and also enables us to examine the causal effect between HSR development and urban economic growth.

The rest of the paper is organized as follows: Section 2 reviews the relevant literature, which will help to understand the linkages among the HSR network, connectivity improvement, and urban economic growth. Section 3 introduces the data characteristics and methodology, Section 4 discusses the empirical results, and Section 5 summarizes and concludes.

\section{$2 \quad$ Literature review}

Following the pioneering work done by Aschauer (1989), who highlighted the importance of public capital (highways, airports, utilities, mass transit, water and sewer systems) on the US economy, quite a few scholars (Holtz-Eakin \& Schwartz, 1995; Baltagi \& Pinnoi, 1995; Bom \& Ligthart, 2014; Calderón, Moral-Benito, \& Servén, 2015; Jia, Zhou, \& Qin, 2017) attempted to further evaluate the economic impact of transportation infrastructure empirically using econometric analysis. Meanwhile, the theoretical framework for transportation infrastructure assessment has expanded as well. For instance, several milestone works, such as Krugman (1991), Ottaviano and Thisse (2002), and Fujita and Thisse (2003) emphasized that transportation cost plays a key role in affecting regional economic activities, such as determining firm location, factor mobility, and the size of market area in the context of an imperfect competition market. Duranton and Turner (2012) considered transportation infrastructure as a factor determining regional labor mobility in their theoretical model, in which they found supportive evidence from the effects of interstate highways on regional employment in the US. Blumenberg and Pierce (2014) found that the improvement of access to public transit would improve labor's mobility and provide multiple benefits, such as job searching and securing existing jobs. These benefits in turn, are considered to have further impacts on society, such as improving the welfare of low-income families. Although some studies highlight the importance of the connectivity improvement brought by newly added transportation infrastructure (Patuelli, Reggiani, Nijkamp, \& Bade, 2010; Parthasarathi, 2014), few studies have actually measured the economic benefits of HSR with a focus on the connectivity improvement. Some studies have attempted to measure the economic impact of HSR with a focus on regional economic growth (Chen, Xue, Rose, \& Haynes, 2016), regional economic disparity (Chen \& Haynes, 2017) integration (Roland-Holst, 2009; Zheng \& Kahn, 2013), skill premia in local labor markets (Michaels, Rauch, \& Redding, 2012), and spatial matching in labor markets (Tikoudis, Sundberg, \& Karlström, 2012). Their conclusions generally show that HSR infrastructure can have a significant impact on regional economic performance.

Despite these early studies providing some evidence to elucidate the economic benefits of the HSR system, one should note that the results from the empirical studies using econometric methods could be questionable given that these studies may suffer from a few statistical issues. For instance, although quite a few studies have attempted to examine the impact of HSR using indicators such as the monetary value of HSR investments and the length of HSR lines, the network characteristics of HSR system improvements, which reflect the quality of the infrastructure network, are often ignored. 
In addition, the heterogeneous effect of transportation infrastructure on regional economic growth is also a concern. As Donaldson and Hornbeck (2016) revealed, the effect of transportation infrastructure on regional economic growth can vary greatly due to different regional characteristics and conditions. Therefore, the quality of transportation needs to be measured carefully in order to reflect the heterogeneous effect of infrastructure systems (Elhorst \& Oosterhaven, 2008). This is true considering that the benefits of transportation networks can sometimes be quite unclear, due to the fact that improved connectivity may reshape the spatial distribution of economic activity and thus widen the gap between core regions and periphery regions (Faber, 2014). Although it is generally expected that all connected regions will receive the benefits of the developed transportation network, it is also likely that some cities may not benefit from the transportation network improvement due to a lack of sufficient conditions (e.g., labor and capital) for economic growth.

Thirdly, the lack of consideration for endogeneity and spatial dependence may also lead to a problematic outcome of the assessment. Specifically, the failure to address the endogeneity issue between transportation infrastructure and economic growth may lead to an inefficient estimation, whereas ignoring spatial dependence may cause a biased estimate since the spatial spillover effects of the transportation network are not captured. Instrumental variable (IV) techniques were generally adopted to solve the endogeneity issue. For instance, various instruments such as spatial distribution of major military troop deployments (Zheng \& Kahn, 2013), the least cost path spanning tree networks (Faber, 2014), straightline instruments (Ghani, Goswami \& Kerr, 2016), and historical railroads network (Zheng \& Kahn, 2013; Baum-Snow, Brandt, Henderson, Turner, \& Zhang, 2014) were adopted in previous empirical work. In terms of spatial dependence, the general approach is to adopt a spatial econometric modeling technique in which the spatial effects of transportation infrastructure and economic performance are captured through spatial weight matrices (Giacinto, Micucci, \& Montanaro, 2010; Tong, Yu, Cho, Jensen, \& Ugarte, 2013). To our limited knowledge, few studies consider these two problems simultaneously. To fill this research gap, we address these two issues using a combination of IV methods and spatial econometric specification (spatial Durbin model). We believe that such an integrated modeling framework provides new insights on clarifying the economic benefits of the HSR network in China.

\section{Data and methodology}

\subsection{Data}

In order to assess the improvement of intercity connectivity brought by HSR in China, a degree centrality measure is adopted by following DeLaurentis, Han, and Kotegawa, (2008), Mishra, Welch, and Jha (2012) and Wang, Song, and Wen (2018). The frequency between nodes are considered the connecting power and the HSR network is considered a weighted network. Hence, the connectivity of city in the HSR network can be defined as follows:

$$
\text { connectivity }_{i, t}=\frac{\sum_{j, i \neq j}^{N} \text { frequency }_{i j, t}}{N-1}
$$

where measures the connectivity ${ }_{i, t}$ of city $i$, frequency ${ }_{i j, t}$ denotes the number of the daily direct HSR services between city $i$ and city $j$, and represents the total number of cities. ${ }^{1}$ Therefore, equation (1) could also be considered a normalized degree centrality based on total number of direct connections to other cities in the network. The larger the value of connectivity ${ }_{i,}$ the more connections city $i$ has in the HSR network. If city $i$ has not been connected within the HSR network, connectivity ${ }_{i, t}$ will be 0 .

\footnotetext{
${ }^{1}$ Considering the data availability, no transfer data is included.
} 
Our investigation covers 268 cities over the period of 2008-2015, which reflects major evolutions in China's HSR network. To provide a comprehensive assessment of the HSR network in China, all the HSR trains (type G, D and C) are considered in the analysis. The descriptive statistics of all the variables are summarized in Table 1. Specifically, the data of HSR service and frequency were obtained from the National Railway Train Schedule, published by the China Railway Press. Other data was obtained from the China City Statistical Yearbooks, 2009-2016. The control variables were selected following the example of Banister and Berechman (2001) and Faber (2014).

Table 1. Descriptive statistics of all the variables

\begin{tabular}{|c|c|c|c|c|c|c|}
\hline Variables & Definition & Num. & Mean & Max. & Min. & Std.Dev. \\
\hline $\ln G D P P C$ & Gross domestic product (GDP) per capita & 2144 & 10.318 & 8.189 & 12.035 & 0.698 \\
\hline connectivity & City's connectivity in HSR network & 2144 & 2.228 & 9.065 & 0.000 & 0.630 \\
\hline ln capital & Capital stock per capita & 2144 & 6.476 & 12.096 & 2.157 & 0.704 \\
\hline $\ln F D I$ & Foreign Direct Investment (FDI) per capita & 2144 & 3.070 & 7.575 & 0.786 & 0.736 \\
\hline ln human & The average years of schooling & 2144 & 2.364 & 2.908 & 2.013 & 0.127 \\
\hline ln indstructure & The ratio of the secondary industry on GDP & 2144 & 3.635 & 4.374 & 2.007 & 0.385 \\
\hline $\ln$ urban & The ratio of urban population in total population & 2144 & 3.016 & 4.512 & 2.026 & 0.534 \\
\hline
\end{tabular}

Note: To ensure the accuracy of the data, the impact of price factor has been removed from the above variables if needed.

\subsection{Specification of the base model}

The base model adopts a reduced form analysis to estimate coefficients that reveal the relationships between connectivity improvement and economic output. The model can be specified as:

$$
\ln \left(G_{D P P C}\right)=\alpha_{0}+\alpha_{1} \text { connectivity }_{i, t}+\alpha_{2} \ln \left(z_{i t}\right)+\varepsilon_{i}+\sigma_{t}+\xi_{i t}
$$

where $i$ and $t$ denote city and time period, respectively. $\ln \left(G D P P C_{i l}\right)$ represents regional economic performance, which is measured by GDP per capita. connectivity ${ }_{i, t}$ denotes the level of connectivity brought by the operations of HSR services. $\ln \left(z_{i t}\right)$ represents the control variables, which include capital

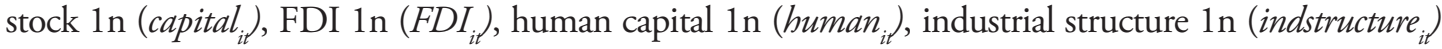
and the level of urbanization $\ln \left(\operatorname{urban}_{i}\right) \cdot \varepsilon_{\mathrm{i}}, \sigma_{\mathrm{t}}$ and $\xi_{\mathrm{it}}$ represent the individual fixed effect, the time fixed effect, and the error term, respectively.

Different interaction terms are also introduced to test whether or not the significance of these variables may enhance the positive effects associated with connectivity improvement. To avoid multicollinearity and provide a robustness check of the various control variables, the interaction items are introduced separately. Thus, the modeling structure could be further expanded as follows:

$$
\begin{aligned}
\ln \left(G^{\prime} P P C_{i t}\right)=\alpha_{0}+ & \alpha_{1} \text { connectivity }_{i, t}+\alpha_{2} \ln \left(z_{i t}\right)+\alpha_{3} \text { connectivity }_{i, t} \\
& \times \ln \left(z_{i t}\right)+\varepsilon_{i}+\sigma_{t}+\xi_{i t}
\end{aligned}
$$

where $\ln \left(z_{i l}\right)$ represents the control variables. connectivity ${ }_{i, t} \times \ln \left(z_{i l}\right)$ represents the interaction item. If the interaction term is significant, the estimated coefficient of connectivity ${ }_{i, t}$ would then be equal to $\alpha_{1}+\alpha_{2} \ln \left(z_{i}\right)$. Hence, the heterogeneous effect of different economic variables on the level of connectivity improvement can be adequately captured. 


\subsection{Specification of the spatial econometric model}

To achieve an accurate assessment of transportation infrastructure's impact on economic growth, one needs to capture both the direct effects (specific identifiable influence of local connectivity improvement) and indirect (spillover) effects simultaneously. The former refers to the influence that is driven by connectivity improvement locally, whereas the latter refers to statistical associations between neighbors' connectivity improvement. Following Tobler's first law of geography: "Everything is related to everything else, but near things are more related than distant things" (Tobler, 1970), we assume that the interaction between a geographic unit and its neighboring units tends be stronger than others. Hence, a binary contiguity matrix is adopted to reflect such a spatial relationship. Specifically, if region $i$ and region $j$ share a common boundary, the corresponding element in the weight matrix is specified as 1 , otherwise 0 .

Different types of spatial interactions are considered in our spatial econometric modeling procedure. These interactions include the effects of endogenous spatial interactions among the dependent variable 1n $\left(G D P P C_{i i}\right)$, the effects of exogenous spatial interactions among independent variables, and the effects of spatial interactions among the error term $\xi_{i t}$ Three different forms of spatial econometric models are adopted to examine the corresponding spatial autocorrelation so as to provide guidance for selecting the appropriate modeling specification.

The effects of endogenous spatial interaction are examined using the spatial autoregressive (SAR) model, in which W1n(GDPPC) is introduced to test whether or not the dependent variable $\ln \left(G D P P C_{i t}\right)$ is statistically significantly influenced by its spatial lag term; in other words, the effect from its neighboring cities. The specification of SAR can be expressed as follows:

$$
\begin{aligned}
\ln \left(G D P P C_{i t}\right)= & \alpha_{0}+\rho \mathbf{W} \mathbf{1 n}(\mathbf{G D P P C})+\alpha_{1} \text { connectivity }_{i, t} \\
& +\alpha_{2} \ln \left(z_{i t}\right)+\varepsilon_{i}+\sigma_{t}+\xi_{i t}
\end{aligned}
$$

where $\mathbf{W}$ is the spatial weight matrix, which is based on the first order rook adjacency relationship as stated above. W1n(GDPPC) represents endogenous spatial interaction effects. $\rho$ denotes the coefficients of the spatial lags to be estimated.

Similiarly, the spatial error model (SEM) is adopted to capture the spatial interaction effects among the error term $\xi_{i t}$, which is specified as $\mathbf{w} \xi$. The SEM model can be written as:

$$
\ln \left(\text { GDPPC }_{i t}\right)=\alpha_{0}+\alpha_{1} \text { connectivity }_{i, t}+\alpha_{2} \ln \left(z_{i t}\right)+\lambda \mathbf{w} \xi+\varepsilon_{i}+\sigma_{t}+\xi_{i t}
$$

In addition, the spatial Durbin model (SDM), which integrates both the spatial lags of dependent variables and independent variables are also adopted. SDM is considered an unrestricted global model, which is capable of providing a comprehensive assessment of various spatial effects (LeSage \& Pace, 2009). The specification is expressed in equation (6).

$$
\begin{gathered}
\ln \left(G D P P C_{i t}\right)=\alpha_{0}+\delta \mathbf{W} \mathbf{1 n}(\mathbf{G D P P C}) \alpha_{1} \text { connectivity }_{i, t}+\alpha_{2} 1 \mathrm{n}\left(z_{i t}\right) \\
+\theta_{1} \mathbf{W c o n n e c t i v i t y}+\theta_{2} \mathbf{W} \mathbf{1 n}(\mathbf{z})+\varepsilon_{i}+\sigma_{t}+\xi_{i t}
\end{gathered}
$$




\section{$4 \quad$ Empirical results}

\subsection{Base model results}

The regression results of the base model are summarized in Table 2. The models were estimated based on an OLS method with individual-fixed effect and time-fixed effect. Specifically, column (1) shows that the coefficient of connectivity is 0.016 and is statistically significant, which confirms that connectivity improvement is positively associated with the change of GDP per capita at the city level. This result suggests that the development of HSR does have a positive effect on promoting urban economic growth due to the improvement of intercity connectivity.

Columns (2) - (6) summarize the results estimated based on equation (3) with different interaction terms. As shown in Table 2, the interaction terms are found to have different effects. For instance, the interaction terms with capital stock, human capital and urbanization are found to be positive and statistically significant, suggesting that the effect of connectivity improvement on GDP per capita is also likely to be influenced by these three variables, interactively. This is understandable as cities with affluent endowments, such as capital and human resources, tend to receive more benefits from connectivity improvement due to the operation of HSR.

Conversely, the estimates of the connectivity variable in columns (2) and (4) are significantly negative. Considering that the corresponding interaction terms are significantly positive, this can be interpreted as only those cities with capital and human resources higher than the threshold values will benefit from the developed HSR network. Considering the fact that the connection to the HSR network makes labor and other economic factors flow to big cities more easily, a subset of small cities with limited capital and human resources may suffer from negative economic growth due to the competitive nature of regional economic activities. Overall, the results provide empirical evidence that the effects of connectivity improvement due to HSR development on urban economic growth does indeed tend to be heterogeneous for small cities and regional hub cities. Thus, from the perspective of heterogeneity, not all cities connected to the HSR network can benefit from it. Compared with non-connected cities, some connected cities with poor economic conditions may endure a negative impact on their economic performance due to the so-called "siphon effect." 
Table 2. Regression results of the base model

\begin{tabular}{|c|c|c|c|c|c|c|}
\hline & $(1)$ & $(2)$ & (3) & $(4)$ & (5) & $(6)$ \\
\hline \multirow[t]{2}{*}{ connectivity } & $0.016^{* * *}$ & $-0.021^{* * *}$ & 0.029 & $-0.009^{* *}$ & 0.030 & $0.033^{*}$ \\
\hline & $(3.39)$ & $(-3.28)$ & $(0.89)$ & $(-1.94)$ & $(0.75)$ & $(1.82)$ \\
\hline \multirow[t]{2}{*}{ In capital } & $0.252^{* * *}$ & $0.023^{* * *}$ & $0.252^{* * *}$ & $0.254^{* * *}$ & $0.252^{* * *}$ & $0.252^{* * *}$ \\
\hline & $(6.83)$ & $(6.52)$ & $(6.83)$ & $(7.35)$ & $(6.81)$ & $(6.74)$ \\
\hline \multirow[t]{2}{*}{ In $F D I$} & 0.015 & 0.015 & 0.006 & 0.016 & 0.015 & 0.015 \\
\hline & $(0.65)$ & $(0.66)$ & $(0.41)$ & $(0.67)$ & $(0.65)$ & $(0.65)$ \\
\hline \multirow[t]{2}{*}{ In buman } & 0.007 & 0.007 & 0.007 & 0.001 & 0.007 & 0.007 \\
\hline & $(0.56)$ & $(0.57)$ & $(0.57)$ & $(0.40)$ & $(0.57)$ & $(0.57)$ \\
\hline \multirow[t]{2}{*}{ In indstructure } & $0.234^{* * *}$ & $0.234^{* * *}$ & $0.233^{* * *}$ & $0.234^{* * *}$ & $0.127^{* * *}$ & $0.233^{* * *}$ \\
\hline & $(4.16)$ & $(4.15)$ & $(4.12)$ & $(4.20)$ & $(4.14)$ & $(4.11)$ \\
\hline \multirow[t]{2}{*}{ In urban } & $0.194^{* *}$ & $0.187^{*}$ & $0.190^{* *}$ & $0.201^{* * *}$ & $0.195^{* *}$ & $0.050^{*}$ \\
\hline & $(2.03)$ & $(1.91)$ & $(2.00)$ & $(2.19)$ & $(2.03)$ & $(1.86)$ \\
\hline \multirow[t]{2}{*}{ connectivity $\times 1$ n Capital } & & $0.031^{\text {** }}$ & & & & \\
\hline & & $(2.00)$ & & & & \\
\hline \multirow[t]{2}{*}{ connectivity $\times \ln F D I$} & & & 0.001 & & & \\
\hline & & & $(0.27)$ & & & \\
\hline \multirow[t]{2}{*}{ connectivity $\times \ln$ human } & & & & $0.080^{* * *}$ & & \\
\hline & & & & $(5.37)$ & & \\
\hline \multirow[t]{2}{*}{ connectivity $\times 1 \mathrm{n}$ indstructure } & & & & & 0.007 & \\
\hline & & & & & (1.16) & \\
\hline \multirow[t]{2}{*}{ connectivity $\times \ln$ urban } & & & & & & $0.013^{* *}$ \\
\hline & & & & & & $(2.58)$ \\
\hline $\mathrm{R}^{2}$ & 0.932 & 0.935 & 0.940 & 0.937 & 0.933 & 0.943 \\
\hline
\end{tabular}

Notes: All regressions have a constant term and include both time fixed effects and individual fixed effects. Heteroscedastic consistent t-statistics are reported in parentheses. ${ }^{* * *} \mathrm{p}<0.01{ }^{* *} \mathrm{p}<0.05 .{ }^{*} \mathrm{p}<0.1$.

\subsection{Addressing the endogeneity}

Ignorance of the endogeneity issue between economic growth and transportation infrastructure may lead to a serious estimation error (Beyzatlar, Karacal, \& Yetkiner, 2014). To guarantee the validity of the econometric analysis, an instrumental variable regression analysis was adopted to address the endogeneity issue. Specifically, two instrumental variables were selected. The first one is the lagged terms of the endogenous variables in the model. According to Bottasso, Conti, Ferrari, and Tei (2014) and Rodríguez-Pose and Peralta (2015), using the lagged endogenous variables as instrumental variables is appropriate because they are less likely to be influenced by the dependent variable; hence, suggesting that there is no correlation between the lagged terms and the error term. The second approach is to use the historical transportation network as an instrumental variable, similar to Zheng and Kahn (2013) and Baum-Snow et al. (2014). Specifically, the length of highways from 1962 to 1985 was adopted as a time-varying instrumental variable for the analysis.

Table 3 summarizes the results of the first stage regression. Both instrumental variables are found to be statistically significant. The coefficients are 0.872 and 0.504 , which confirms that the selected instrumental variables are not weak instruments. Table 3 also summarizes the test results for both endogeneity and validity of the instrumental variables. Specifically, the Durbin-Wu-Hansen (DWH) test 
is introduced to test whether or not the endogeneity issue exists in our analysis. The result shows the null hypothesis that the explanatory variables are exogenous is rejected, which suggests that an instrumental variable estimation is needed to address the endogeneity issue. The second test is the first-stage F-statistics, which examines the relevance of the instrumental variables being selected. The value of F-statistic is 384.725, suggesting that the null hypothesis of weak instruments is rejected. In addition, the Hansen test and the Sargen test are used to examine the exogeneity of the instrumental variables by testing whether or not the instrumental variables are uncorrelated with the error term. The p-values of both tests are larger than 0.05 , which suggests that null hypothesis that the instrumental variables satisfy the exogeneity condition cannot be rejected. Overall, the results indicate that the instrumental variables being selected are valid to address the endogeneity issue appropriately in the empirical analysis.

Table 3. Tests for endogeneity and validity of instrumental variables

\begin{tabular}{lcc}
\hline Variable and Test Type & Coefficient or Test value & P value \\
\hline The lagged term of connectivity & 0.872 & 0.000 \\
Historical transportation network & 0.504 & 0.021 \\
Endogeneity DWH test & 17.025 & 0.000 \\
Weak-identification F-statistic & 384.725 & \\
Hansen test & 0.752 & 0.436 \\
Sargan test & 0.663 & 0.491 \\
\hline
\end{tabular}

Table 4 presents the regression results using the instrumental variable estimation method. In general, the results after addressing the endogeneity issue are consistent with the estimates in the base model. The estimated coefficient of the connectivity index in model 7 remains statistically significant and positive, with a value of 0.017 . The interaction terms with capital stock, human capital, and urbanization are also significantly positive, which further confirms that these factors do have an influence on the estimate of connectivity index. Overall, the results suggest that the connectivity improvement brought by HSR does have a significant impact on urban economic performance. 
Table 4. Results of the instrumental variables estimation

\begin{tabular}{|c|c|c|c|c|c|c|}
\hline & (7) & (8) & (9) & $(10)$ & $(5)$ & $(6)$ \\
\hline \multirow[t]{2}{*}{ connectivity } & $0.017^{* * *}$ & $-0.018^{* * *}$ & 0.024 & $-0.013^{* *}$ & 0.026 & $0.030^{*}$ \\
\hline & 3.87 & $(-2.80)$ & $(0.80)$ & $(-1.95)$ & $(0.71)$ & $(1.81)$ \\
\hline \multirow[t]{2}{*}{ 1n capital } & $0.266^{* * *}$ & $0.020^{* * *}$ & $0.261^{* * *}$ & $0.263^{* * *}$ & $0.258^{* * *}$ & $0.251^{* * *}$ \\
\hline & $(6.02)$ & $(6.41)$ & $(5.67)$ & $(6.06)$ & $(5.73)$ & (5.63) \\
\hline \multirow[t]{2}{*}{ ln $F D I$} & 0.008 & 0.009 & 0.005 & 0.008 & 0.013 & 0.011 \\
\hline & $(0.41)$ & $(0.43)$ & $(0.37)$ & $(0.40)$ & $(0.69)$ & $(0.65)$ \\
\hline \multirow[t]{2}{*}{ 1n human } & 0.006 & 0.007 & 0.007 & 0.001 & 0.007 & 0.007 \\
\hline & $(0.53)$ & $(0.52)$ & $(0.54)$ & $(0.06)$ & $(0.58)$ & $(0.58)$ \\
\hline \multirow[t]{2}{*}{ 1n indstructure } & $0.217^{* * *}$ & $0.216^{* * *}$ & $0.210^{* * *}$ & $0.210^{* * *}$ & $0.123^{* * *}$ & $0.217^{* * *}$ \\
\hline & $(4.38)$ & $(4.06)$ & $(3.77)$ & $(3.75)$ & $(2.52)$ & $(4.36)$ \\
\hline \multirow[t]{2}{*}{ 1n urban } & $0.190^{* *}$ & $0.188^{*}$ & $0.190^{* *}$ & $0.200^{* * *}$ & $0.196^{* *}$ & $0.049^{*}$ \\
\hline & $(2.00)$ & $(1.93)$ & $(2.00)$ & $(2.17)$ & $(2.04)$ & $(1.85)$ \\
\hline \multirow[t]{2}{*}{ connectivity $\times 1$ ln Capital } & & $0.026^{*}$ & & & & \\
\hline & & $(1.83)$ & & & & \\
\hline \multirow[t]{2}{*}{ connectivity $\times \ln F D I$} & & & 0.001 & & & \\
\hline & & & $(0.16)$ & & & \\
\hline \multirow[t]{2}{*}{ connectivity $\times 1 \mathrm{n}$ human } & & & & $0.083^{* * *}$ & & \\
\hline & & & & $(6.01)$ & & \\
\hline \multirow[t]{2}{*}{ connectivity $\times 1 \mathrm{n}$ indstructure } & & & & & 0.006 & \\
\hline & & & & & $(1.07)$ & \\
\hline \multirow[t]{2}{*}{ connectivity $\times 1 \mathrm{n}$ urban } & & & & & & $0.019^{* *}$ \\
\hline & & & & & & $(2.38)$ \\
\hline $\mathrm{R}^{2}$ & 0.920 & 0.935 & 0.940 & 0.937 & 0.933 & 0.943 \\
\hline
\end{tabular}

Notes: All regressions have a constant term and include both time fixed effects and individual fixed effects. Heteroscedastic consistent t-statistics are reported in parentheses. ${ }^{* * *} \mathrm{p}<0.01 .{ }^{* *} \mathrm{p}<0.05 .{ }^{*} \mathrm{p}<0.1$.

\subsection{Results of spatial econometric model}

Spatial econometric methods are adopted to reveal direct and indirect economic effects of the HSR network. Considering that some critics of spatial econometrics point out that a lot of research applying spatial econometrics is "pointless" due to identification problems (Gibbons \& Overman, 2012), a feasible method is applying experimentalist approaches to spatial econometrics using instrumental variable regression analysis. Table 5 presents the results of different spatial econometric models with and without instrumental variables. The analysis was conducted using instrumental variables - the generalized method of moments (IV-GMM) and the maximum likelihood estimation (MLE), respectively. Although LeSage and Pace (2009) recommended the spatial Durbin model (SDM), the Wald and Likelihood Ratio $(L R)$ tests were applied to identify which spatial model is more appropriate. Both the Wald test and the $L R$ test show that the null hypothesis should be rejected. In other words, the spatial Durbin model cannot be simplified to either a spatial lag model (SAR) or a spatial error model (SEM). 
Table 5. Results of different spatial econometric models with spatial fixed effects

\begin{tabular}{|c|c|c|c|c|c|c|}
\hline & \multicolumn{3}{|l|}{ MLE } & \multicolumn{3}{|l|}{ IV-GMM } \\
\hline & SAR & SEM & SDM & SAR & SEM & SDM \\
\hline \multirow[t]{2}{*}{ connectivity } & $0.160^{*}$ & $0.153^{* * *}$ & $0.101^{*}$ & $0.158^{*}$ & $0.152^{* * *}$ & $0.093^{*}$ \\
\hline & $(1.94)$ & $(6.05)$ & $(1.92)$ & $(1.89)$ & $(5.99)$ & $(1.90)$ \\
\hline \multirow[t]{2}{*}{ In capital } & $0.285^{* * *}$ & $0.266^{* * *}$ & $0.196^{* * *}$ & $0.286^{* * *}$ & $0.267^{* * *}$ & $0.195^{* * *}$ \\
\hline & $(12.33)$ & (10.79) & $(8.30)$ & $(12.41)$ & $(10.80)$ & $(8.26)$ \\
\hline \multirow[t]{2}{*}{ In $F D I$} & 0.017 & $0.018^{*}$ & $0.024^{* *}$ & 0.017 & $0.019^{* *}$ & $0.027^{* *}$ \\
\hline & $(1.03)$ & $(1.89)$ & $(2.02)$ & $(1.05)$ & $(2.00)$ & $(2.13)$ \\
\hline \multirow[t]{2}{*}{ In human } & 0.109 & 0.112 & 0.087 & 0.210 & 0.111 & 0.109 \\
\hline & $(1.30)$ & $(1.51)$ & $(0.65)$ & $(1.32)$ & $(1.50)$ & $(0.71)$ \\
\hline \multirow[t]{2}{*}{ In indstructure } & $0.087^{*}$ & $0.090^{* *}$ & 0.063 & $0.083^{*}$ & $0.091^{* *}$ & 0.060 \\
\hline & $(1.86)$ & $(2.01)$ & $(1.66)$ & $(1.85)$ & $(2.02)$ & $(1.57)$ \\
\hline \multirow[t]{2}{*}{ In urban } & $0.039^{* *}$ & $0.031^{* * *}$ & $0.023^{*}$ & $0.037^{*}$ & $0.030^{* * *}$ & $0.025^{*}$ \\
\hline & $(2.12)$ & $(3.03)$ & $(1.90)$ & $(1.92)$ & $(3.01)$ & $(1.93)$ \\
\hline \multirow[t]{2}{*}{$W^{*}$ connectivity } & & & $0.005^{*}$ & & & $0.004^{*}$ \\
\hline & & & (1.89) & & & $(1.86)$ \\
\hline \multirow[t]{2}{*}{$W^{*} 1 \mathrm{n}$ capital } & & & 0.017 & & & 0.012 \\
\hline & & & $(0.21)$ & & & $(0.18)$ \\
\hline \multirow[t]{2}{*}{$W^{*} \ln F D I$} & & & $-0.012^{* * *}$ & & & $-0.010^{* * *}$ \\
\hline & & & $(-3.32)$ & & & $(-3.17)$ \\
\hline \multirow[t]{2}{*}{$W^{*} 1 \mathrm{n}$ human } & & & -0.053 & & & -0.048 \\
\hline & & & $(-0.27)$ & & & $(-0.16)$ \\
\hline \multirow[t]{2}{*}{$W^{*} 1 \mathrm{n}$ indstructure } & & & 0.004 & & & 0.004 \\
\hline & & & $(1.30)$ & & & $(1.31)$ \\
\hline \multirow[t]{2}{*}{$W^{*} \ln u r b a n$} & & & 0.127 & & & 0.121 \\
\hline & & & $(1.57)$ & & & $(1.50)$ \\
\hline \multirow[t]{2}{*}{$W^{*} G D P P C$} & $0.020^{* * *}$ & & $0.013^{* * *}$ & $0.021^{* * *}$ & & $0.014^{* * *}$ \\
\hline & $(4.07)$ & & $(4.65)$ & $(4.03)$ & & $(4.70)$ \\
\hline $\mathrm{R}^{2}$ & 0.954 & 0.963 & 0.985 & 0.954 & 0.962 & 0.987 \\
\hline Wald test & & & 46.59 & & & 47.34 \\
\hline (spatial lag) & & & $(\mathrm{P}=0.00)$ & & & $(\mathrm{P}=0.00)$ \\
\hline LR & & & 49.67 & & & 50.03 \\
\hline (spatial lag) & & & $(\mathrm{P}=0.00)$ & & & $(\mathrm{P}=0.00)$ \\
\hline Wald test & & & 77.60 & & & 76.51 \\
\hline (spatial error) & & & $(\mathrm{P}=0.00)$ & & & $(\mathrm{P}=0.00)$ \\
\hline LR & & & 82.04 & & & 83.17 \\
\hline (spatial error) & & & $(\mathrm{P}=0.00)$ & & & $(\mathrm{P}=0.00)$ \\
\hline
\end{tabular}

Notes: All regressions have a constant term and include both time fixed effects and individual fixed effects. Heteroscedastic consistent $\mathrm{t}$-statistics are reported in parentheses. ${ }^{* * *} \mathrm{p}<0.01{ }^{* *} \mathrm{p}<0.05 .{ }^{*} \mathrm{p}<0.1$. 
One should note that estimates from spatial econometric models cannot be interpreted in the same way as non-spatial regression models. This is because spatial modeling specifications requires us to decompose the coefficients into direct and indirect effects, which can be recognized as local versus spillover effects. Following LeSage and Pace (2009), the decomposed spatial effects of the SDM model are summarized in Table 6.

The results based on both the MLE and IV-GMM methods demonstrate similar outcomes, which re-confirms the robustness of our empirical analysis. The direct effects of the connectivity variable are statistically significant and positive, suggesting that connectivity improvement due to the operation of HSR has a positive effect on promoting urban economic growth locally. It should be noted that the direct effect estimates of the connectivity variable from the spatial econometric models are relatively larger than those from the non-spatial regression model. Such a difference could be due to the positive feedback effect captured in the spatial modeling framework. Hence, without considering the feedback effect, the effect of HSR would be underestimated.

The indirect effects of the connectivity variable are found to be 0.007 (in MLE) and 0.005 (in IVGMM), respectively, accounting for only approximately $5.8 \%$ of the direct effects. The findings suggest that the improvement of intercity connectivity brought by HSR can yield a mild positive spillover effect on neighboring cities. The research finding is consistent with our intuition, as an improvement of HSR connectivity with nearby cities is likely to improve local transportation conditions, which in turn tends to generate a positive impact on local economic growth.

Overall, the total effects of the connectivity variable are found to be positive and significant, which again confirms an overall positive effect of HSR development on urban economic growth.

Table 6. Decomposed spatial effects based on the spatial Durbin model

\begin{tabular}{|c|c|c|c|c|}
\hline \multirow{2}{*}{$\begin{array}{l}\text { Model } \\
\text { Direct Effects }\end{array}$} & \multicolumn{2}{|c|}{ MLE } & \multicolumn{2}{|c|}{ IV-GMM } \\
\hline & Coef. & t-stat & Coef. & t-stat \\
\hline connectivity & $0.103^{* *}$ & 2.01 & $0.104^{*}$ & 1.92 \\
\hline 1n capital & $0.203^{* * *}$ & 10.04 & $0.196^{* * *}$ & 8.17 \\
\hline 1n $F D I$ & $0.026^{*}$ & 1.84 & $0.029^{*}$ & 1.90 \\
\hline 1n human & 0.131 & 0.25 & 0.139 & 0.28 \\
\hline 1n indstructure & $0.091^{* *}$ & 1.99 & $0.084^{*}$ & 1.86 \\
\hline 1n urban & $0.039^{* * *}$ & 3.55 & $0.046^{* * *}$ & 4.08 \\
\hline \multicolumn{5}{|l|}{ Indirect Effects } \\
\hline connectivity & $0.007^{* *}$ & 2.07 & $0.005^{*}$ & 1.89 \\
\hline 1n capital & 0.016 & 0.82 & 0.013 & 0.61 \\
\hline 1n $F D I$ & $-0.010^{*}$ & -1.93 & $-0.009^{*}$ & -1.82 \\
\hline 1n human & -0.051 & -0.36 & -0.045 & -0.27 \\
\hline 1n indstructure & $0.008^{* *}$ & 2.00 & $0.006^{*}$ & 1.92 \\
\hline 1n urban & 0.112 & 1.03 & 0.110 & 0.94 \\
\hline \multicolumn{5}{|l|}{ Total Effects } \\
\hline connectivity & $0.110^{* * *}$ & 3.52 & $0.109^{* * *}$ & 3.26 \\
\hline 1n capital & $0.219^{* * *}$ & 7.05 & $0.209^{* * *}$ & 6.83 \\
\hline 1n $F D I$ & 0.016 & 1.13 & 0.020 & 1.22 \\
\hline 1n human & 0.080 & 0.96 & 0.94 & 1.34 \\
\hline 1n indstructure & $0.099^{* *}$ & 2.10 & $0.090^{* *}$ & 1.97 \\
\hline 1n urban & $0.151^{* * *}$ & 3.63 & $0.156^{* * *}$ & 3.90 \\
\hline
\end{tabular}

Notes: ${ }^{* * *} \mathrm{p}<0.01 .{ }^{* *} \mathrm{p}<0.05 .{ }^{*} \mathrm{p}<0.1$. 


\section{Conclusion}

Despite the fact that interest in understanding the economic benefits of the HSR network is on the rise, little empirical work has been done with a focus on examining the impact of HSR as a result of the change in intercity connectivity. This is partially due to the complicated nature of statistical analysis in this case, given the presence of issues such as heterogeneous effects, endogeneity, and spatial dependence. Our study aims to fill this gap by providing some new evidence, with a focus on examining the impact of HSR on urban economic growth using the change of intercity connectivity as an indicator. Based on panel data that covers 268 Chinese cities from 2008-2015, our study shows that the improvement of intercity connectivity brought by HSR has a significant and positive effect on urban economic growth. In addition, our analysis also reveals that the heterogeneous effects manifested by various regional economic characteristics, such as capital stock, human capital, and urbanization, do have a strong influence on the empirical analysis. Without considering these effects, the results could be spurious.

In addition, this study also confirms that endogeneity and spatial dependence do exist in our case. Using the IV-GMM method and spatial econometric regression analysis, our study reveals the detailed regional effect of HSR, measured in terms of the direct effect, indirect (spillover) effect, and total effect. In general, the result shows that most contributions from HSR to urban economic growth are generated from a direct (local) effect rather than a spillover effect. Such a finding is different from earlier work that examined the impact of HSR on a provincial level, such as Chen and Haynes (2017), which could be due to the fact that a relatively smaller geographic scale was adopted in our case. Hence, our results reflect a dominant local effect, whereas the spillover effect of HSR on urban economic growth can be limited at city-level analysis. Another reason for such a strong local effect but a mild spillover effect could be due to the fact that the time frame of our study is relatively short; not many HSR lines were in operation until after 2015. Hence, our analysis may only reflect the influence of connectivity improvement on urban economic growth at an early stage of HSR deployment. It would be interesting to revisit this issue after the system is in operation for a longer period of time. In particular, it would be valuable to examine whether or not the spillover effects will play a more significant role as more people begin to ride HSR. Furthermore, the spillover effects under other channels can be examined using different matrices in spatial econometric models, which is also the direction and focus of our future research.

\section{Acknowledgements}

This research was supported by the Shantou university scientific research foundation project (Grant No. STF18010). The authors would like to thank the participants of "The Second Symposium on China's High-Speed Railway Network” for their helpful comments to improve the manuscript. 


\section{References}

Alstadt, B., Weisbrod, G., \& Cutler, D. (2012). Relationship of transportation access and connectivity to local economic outcomes: Statistical analysis. Transportation Research Record, 2297, 154-162.

Ansar, A., Flyvbjerg, B., Budzier, A., \& Lunn, D. (2016). Does infrastructure investment lead to economic growth or economic fragility? Evidence from China. Oxford Review of Economic Policy, 32(3), 360-390.

Aschauer, D. (1989). Is public expenditure productive? Journal of Monetary Economics, 23, 177-200.

Baltagi, B. H., \& Pinnoi, N. (1995). Public capital stock and state productivity growth: Further evidence from an error components model. Empirical Economics, 20(2), 351-359.

Banister, D., \& Berechman, Y. (2001). Transport investment and the promotion of economic growth. Journal of Transport Geography, 9(3), 209-218.

Baum-Snow, N. (2013). Urban transport expansions, employment decentralization, and the spatial scope of agglomeration economies (Working paper). Brown University, Providence, RI.

Baum-Snow, N., Brandt, L., Henderson, V. J., Turner, M. A., \& Zhang, Q. (2014). Transport infrastructure, urban growth and market access in China (Working paper). Brown University, Providence, RI.

Beyzatlar, M. A., Karacal, M., \& Yetkiner, H. (2014). Granger-causality between transportation and GDP: A panel data approach. Transportation Research Part A: Policy and Practice, 63, 43-55.

Blumenberg, E., \& Pierce, G. (2014). A driving factor in mobility? Transportation's role in connecting subsidized housing and employment outcomes in the Moving to Opportunity (MTO) program. Journal of the American Planning Association, 80(1), 52-66.

Bom, P. R. D., \& Ligthart, J. E. (2014). What have we learned from three decades of research on the productivity of public capital? Journal of Economic Surveys, 28(5), 889-916.

Bottasso, A., Conti, M., Ferrari, C., \& Tei, A. (2014). Ports and regional development: A spatial analysis on a panel of European regions. Transportation Research Part A: Policy and Practice, 65, 44-55.

Calderón, C., Moral-Benito, E., \& Servén, L. (2015). Is infrastructure capital productive? A dynamic heterogeneous approach. Journal of Applied Econometrics, 30(2), 1-34.

Chatman, D. G. (2014). Estimating the effect of land use and transportation planning on travel patterns: Three problems in controlling for residential self-selection. Journal of Transport and Land Use, $7(3), 47-56$.

Chen, Z., \& Haynes, K. E. (2015). Public surface transportation and regional output: A spatial panel approach. Papers in Regional Science, 94(4), 727-751.

Chen, Z., \& Haynes, K. E. (2017). Impact of high-speed rail on regional economic disparity in China. Journal of Transport Geography, 65, 80-91.

Chen, Z., Xue, J., Rose, A. Z., \& Haynes, K. E. (2016). The impact of high-speed rail investment on economic and environmental change in China: A dynamic CGE analysis. Transportation Research Part A: Policy and Practice, 92, 232-245.

DeLaurentis, D., Han, E. P., \& Kotegawa, T. (2008). Network-theoretic approach for analyzing connectivity in air transportation networks. Journal of aircraft, 45(5), 1669-1679.

Donaldson, D., \& Hornbeck, R. (2016). Railroads and American economic growth: A "market access" approach. The Quarterly Journal of Economics, 131(2), 799-858.

Duranton, G., \& Turner, M. A. (2012). Urban growth and transportation. Review of Economic Studies, 79(4), 1407-1440.

Elhorst, J. P., \& Oosterhaven, J. (2008). Integral cost-benefit analysis of Maglev Rail projects under market imperfections. Journal of Transport and Land Use, 1(1), 65-87.

Faber, B. (2014). Trade integration, market size, and industrialization: Evidence from China's National Trunk Highway System. The Review of Economic Studies, 81(3), 1046-1070. 
Fujita, M., \& Thisse, J. F. (2003). Does geographical agglomeration foster economic growth? And who gains and loses from it? The Japanese Economic Review, 54(2), 121-145.

Ghani, E., Goswami, A. G., \& Kerr, W. R. (2016). Highways and spatial location within cities: Evidence from India. The World Bank Economic Review, 30(S1), S97-S108.

Giacinto, V. D., Micucci, G., \& Montanaro, P. (2010). Dynamic macroeconomic effects of public capital: Evidence from regional Italian data. Giornale Degli Economisti E Annali Di Economia, 69(1), 29-66.

Gibbons, S., \& Overman, H. G. (2012). Mostly pointless spatial econometrics? Journal of Regional Science, 52(2), 172-191.

Graham, D. J., \& Dender, K. V. (2011). Estimating the agglomeration benefits of transport investments: Some tests for stability. Transportation, 38(3), 409-426.

Handy, S., Cao, X., \& Mokhtarian, P. (2005). Correlation or causality between the built environment and travel behavior? Evidence from Northern California. Transportation Research Part D Transport \& Environment, 10(6), 427-444.

Holtz-Eakin, D., \& Schwartz, A. E. (1995). Infrastructure in a structural model of economic growth. Regional Science and Urban Economics, 25(2), 131-151.

Jia, S., Zhou, C., \& Qin, C. (2017). No difference in effect of high-speed rail on regional economic growth based on match effect perspective? Transportation Research Part A: Policy and Practice, 106, 144-157.

Krugman, P. (1991). Increasing returns and economic geography. Journal of Political Economy, 99(3), 483-499.

Lesage, J., \& Pace, R. K. (2009). Introduction to spatial econometrics. Boca Raton, FL: CRC Press.

Lin, Y. (2017). Travel costs and urban specialization patterns: Evidence from china's high-speed railway system. Journal of Urban Economics, 98(C), 98-123.

Michaels, G., Rauch, F., \& Redding, S. J. (2012). Urbanization and structural transformation. The Quarterly Journal of Economics, 127(2), 535-586.

Mishra, S., Welch, T. F., \& Jha, M. K. (2012). Performance indicators for public transit connectivity in multi-modal transportation networks. Transportation Research Part A: Policy and Practice, 46(7), $1066-1085$.

Morten, M., \& Oliveira, J. (2016). Paving the way to development: Costly migration and labor market integration (NBER working paper, No. 22158). National Bureau of Economic Research, Cambridge, MA.

Ottaviano, G. I. P., \& Thisse, J. F. (2002). Integration, agglomeration and the political economics of factor mobility. Journal of Public Economics, 83(3), 429-456.

Parthasarathi, P. (2014). Network structure and metropolitan mobility. Journal of Transport and Land Use, 7(2), 153-170.

Patuelli, R., Reggiani, A., Nijkamp, P., \& Bade, F. J. (2010). The evolution of the commuting network in Germany: Spatial and connectivity patterns. Journal of Transport and Land Use, 2(3/4), 5-37.

Qin, Y. (2017). No county left behind? The distributional impact of high-speed rail upgrades in China. Journal of Economic Geography, 17(3), 489-520.

Rodríguez-Pose, A., \& Peralta, E. M. V. (2015). Innovation and regional growth in Mexico: 20002010. Growth \& Change, 46(2), 172-195.

Roland-Holst, D. (2009). Infrastructure as a catalyst for regional integration, growth, and economic convergence: Scenario analysis for Asia. From growth to convergence. London: Palgrave Macmillan.

Tikoudis, I., Sundberg, M., \& Karlström, A. (2012). The effects of transport infrastructure on regional economic development: A simulated spatial overlapping generations model with heterogenous skill. Journal of Transport and Land Use, 5(2), 77-101. 
Tobler, W. R. (1970). A computer movie simulating urban growth in the Detroit region. Economic Geography, 46, 234-240.

Tong, T., Yu, T. H. E., Cho, S. H., Jensen, K., \& Ugarte, D. D. L. T. (2013). Evaluating the spatial spillover effects of transportation infrastructure on agricultural output across the united states. Journal of Transport Geography, 30(3), 47-55.

Wang, H., Song, Z., \& Wen, R. (2018). Modeling air traffic situation complexity with a dynamic weighted network approach. Journal of Advanced Transportation, Article ID 5254289.

Zhang, L., Hong, J. H., Nasri, A., \& Shen, Q. (2012). How built environment affects travel behavior: A comparative analysis of the connections between land use and vehicle miles traveled in U.S. cities. Journal of Transport and Land Use, 5(3), 40-52.

Zhang, W. B. (2013). The impact of transport, land and fiscal policy on housing and economic geography in a small, open growth model. Journal of Transport and Land Use, 6(1), 89-100.

Zheng, S., \& Kahn, M. E. (2013). China's bullet trains facilitate market integration and mitigate the cost of megacity growth. Proceedings of the National Academy of Sciences, 110(14), E1248-E1253. 